\title{
Analysis on the Resource Advantages in the Construction of Aba Sub-plateau Training Base
}

\author{
Dequan Wan \\ School of Physical Education and Health, Aba Teachers University, Wenchuan, Sichuan, China 623002
}

\begin{abstract}
Sub-plateau training is a special training method of plateau training, and its effect has been gradually approved by the sports community. This paper conducts feasibility analysis from the perspective of relevant factors of sports resource evaluation such as plateau training theory and sub-plateau geographical environment, and combined with the regional advantages and national characteristics of the construction of Aba base, proposes the idea of constructing Aba sub-plateau training base based on the plateau training theory and the construction status of Chinese sub-plateau bases.
\end{abstract}

Keywords: Aba; Sub-plateau; Plateau training theory; Base construction; Feasibility.

The effect of sub-plateau training in sports is unanimously recognized by the sports community. The altitude of the sub-plateau is relatively low, and the training in the sub-plateau region has a certain degree of hypoxia stimulation. As the degree of hypoxia is not deep and the stimulation to the body is not very obvious, athletes can go directly to normal training from the plain to the sub-plateau, without having to go through a one-week adaptation period, and the load can be close to the plain level. From the perspective of the combination of physiological functions and exercise training, the athletes can maintain the training intensity of the plains in the sub-plateau training, which can avoid the unfavorable factors in the plateau training and improve the athletic ability.

\section{Plateau and sub-plateau training theory}

Studies show that the plateau above $1500 \mathrm{~m}$ has the largest stimulation degree to the body, and $1500 \mathrm{~m}$ is a threshold altitude, that is, above this height, the maximum oxygen uptake of the human body will decrease linearly with height, and the VO2max will drop by $1 \%$ with every height increase of $100 \mathrm{~m}$. It is generally believed that the areas with the altitude between 500 and $1500 \mathrm{~m}$ are defined as the sub-plateau, and the suitable height of the sub-plateau training is between 1200 and $2200 \mathrm{~m}$.

The mechanism research of traditional plateau training finds that it is difficult for athletes to maintain the same training intensity as that in plains in plateau training. The hypoxia caused by high altitude leads to low muscle blood flow and protein synthesis, thinner muscle fibers and muscle atrophy, as well as loss of muscle strength, resulting in loss of speed. Plateau training requires a lot from the body, and the weight of the players would be significantly reduced; in the plateau training, some technically strong items such as shooting, throwing, etc., because of the gravity change of the Earth, wind and wind directions on the plateau and atmospheric pressure, will have motion deformation to a certain extent, thus affecting the technical actions.

The high living-low training (HiLo) method has better effect than the plateau training method in a way. However, the "optimal height" of plateau training has always been an important topic in plateau training research. Trained in the low-pressure hypoxia environment of the plateau, and using the double stimulation of altitude hypoxia and exercise, the athletes have strong stress response, including accelerated respiratory rate and heart rate, increased blood vessel volume and thickened blood vessels, their cardiovascular system is exercised, oxygen uptake and hemoglobin concentration increases, the body's ability to withstand lactic acid are enhanced, and the body's functional potential is mobilized, resulting in a series of anti-hypoxia physiological responses that are conducive to improving exercise capacity.

\section{The status of Chinese sub-plateau training bases}

Qingzhen Sports Training Base and Hongfeng Lake Water Sports Training Base in Guizhou Province have been designated by the State General Administration of 
Sport as national-level sub-plateau training bases and also the training bases used to prepare for the 2008 Olympic Games. Systematic research on sub-plateau training explores the characteristics and mechanisms of sub-plateau training as well as the laws of sub-plateau training. Kunming in Yunnan, Douba in Qinghai and Yuzhong in Gansu are three famous plateau training bases in China. The altitude of Yuzhong Base in Gansu Province is on staged rise, thus having certain advantages in training. Different forms and methods are needed in the training, such as high and low alternating training, shuttle training, high and level alternating training, high living-low training, and low living-high training. On the site selection of the plateau training base, the plateau training base group with a relatively close distance to each other, stepped distribution and a relatively high elevation difference is an ideal sub-plateau sports training area. For example, the construction of the Gansu sub-plateau base centers on Yuzhong, and the elevation of Lanzhou-Yuzhong-Xinglongshan plateau training community increases from $1540 \mathrm{~m}, 1996 \mathrm{~m}, 2200 \mathrm{~m}$ to $2800 \mathrm{~m}$, which is suitable for conducting staged plateau training and shuttle type.

\section{Analysis on the resource advantages in the construction of Aba sub-plateau training base}

\subsection{Special geographical location that is suitable for base construction}

The Stuart International Plateau Symposium in 1997 defined that the most ideal plateau training should be carried out on the moderate plateau with the altitude of 2000-2500 m. In recent years, the international community has basically agreed that the optimal height of athletes' training in the plateau is $2200-2500 \mathrm{~m}$. Below 2200 meters, low-pressure hypoxia stimulation is less, which is not conducive to fully explore the potential of the body; above 2500 meters, it is difficult for the body to withstand large training load, which is not conducive to recovery after training. At the same time, studies have shown that the most appropriate duration should be 4-6 weeks. Too short plateau training time is not conducive for the body to generate adaptive changes; too long plateau training time is not conducive to the body's adaptive change after returning to the plain. Wenchuan, Lixian and Maoxian belong to the sub-plateau, the remarkable vertical zonality plays an obvious role in helping the athletes to improve the body's metabolic level and promote the change of physiological functions, which has practical and widespread advantages from the perspective of sports training science.

\subsubsection{Geographical environment of Barkam County}

The elevation of Barkam County is 2,600 meters, which is the ideal height for plateau training. Barkam Town is the residence of the Aba Tibetan and Qiang Autonomous Prefecture, the political, cultural, financial and information center of the whole prefecture, and 365 kilometers away from the provincial capital, Chengdu. The county has convenient transportation, and the national highway 317 runs through the whole territory. The mobile phone, program-controlled telephone and wireless paging network cover the urban area and all towns and villages, while the comprehensive coverage rate of radio and television reaches $100 \%$.

Barkam is located in the central part of the autonomous prefecture, bordering Hongyuan and Lixian in the east, Jinchuan and Xiaojin in the south, Rangtang in the west and Hongyuan and Aba in the north. Its geographical coordinates are $30^{\circ} 35^{\prime} \sim 32^{\circ} 24^{\prime}$ north latitude, $101^{\circ} 17^{\prime} \sim 102^{\circ} 41^{\prime}$ east longitude. It is 134 kilometers long from east to west, and 90 kilometers wide from north to south, covering an area of 6,632.73 square kilometers. It is located in the northwestern part of the Sichuan Basin and the eastern part of the Qinghai-Tibetan Plateau, belonging to plateau valley area. The terrain is irregularly rectangular, and the terrain gradually decreases from northeast to southwest. The highest peak in the territory is about 5,000 meters height, and the lowest valley is about 2300 meters.

\subsubsection{Geographical environment of Maoxian County}

Maoxian (formerly Maowen Qiang Autonomous County) is located in the northwestern part of Sichuan Province, southeast of Aba Prefecture. It is affiliated to the Aba Tibetan and Qiang Autonomous Prefecture of Sichuan Province and is located at $103.8^{\circ}$ east longitude and $31.6^{\circ}$ north latitude. The county has undulating hills and valleys and steep mountains, and the terrain is gradually raised from the southeast to northwest. The end part of Longmen Mountains and the Minshan Mountain of Qionglai Mountains run through the whole territory. The highest elevation is 5,230 meters, the lowest elevation is 900 meters, and the relative height difference is 4,094 meters. It is a typical alpine valley area. The county is 1,580 meters above sea level, with an average annual temperature of $11.0^{\circ} \mathrm{C}$.

\subsubsection{Geographical environment of Wenchuan County}

Wenzhou Town, Wenchuan County is located at the intersection of Minjiang River and Zagunao River in the northern part of the county. It is 1325 meters above sea level and is surrounded by many mountain ranges such as Chaping Mountain Range and Qionglai Mountain Range. It is 146 kilometers away from Chengdu and 246 kilometers away from Barkam. The 213, 317 national highways pass through the county. It is located at $103.61^{\circ}$ east longitude, $31.46^{\circ}$ north latitude. Wenchuan Sub-plateau training base has moderate altitude, with a large gradient and a unique geographical environment. The geographical position is 100 to 180 kilometers from the plain and 100 to 200 kilometers from the plateau, which is conducive to the implementation of "high living and low training" or "low living and high training". It can adapt to the different requirements of plateau training, so 
that the coaches can carry out "high-high alternation" and "plateau-sub-plateau-plain" cross training according to the training needs.

\subsection{A large number of advanced sports facilities built after the earthquake}

Before the Wenchuan earthquake, sports facilities in Wenchuan, Lixian and Maoxian were relatively backward. After the earthquake, a large number of advanced stadiums were built with the support of the assisting provinces and municipalities, but the utilization rate needs to be improved. After the completion of the base, it will become a comprehensive training base with both the plateau and the sub-plateau advantages. The Aba Teachers University was rebuilt in Shuimo Town, Wenchuan County. China invested nearly 800 million yuan in total to rebuild the school, in which the sports facilities include comprehensive gymnasium, multi-functional training hall, standard track and field stadium, football field and so on. In 2010, the state added 30 million yuan more to build ethnic sports training hall for the training of superior items such as putting rod, high-speed racing, shuttlecock, Yajia and other traditional sports of Tibet and Qiang.

Table 1. Newly-built sports venues after the earthquake by Maoxian Cultural and sports bureau.

\begin{tabular}{|c|c|c|c|c|}
\hline Project name & Construction site & $\begin{array}{c}\text { Construction } \\
\text { content }\end{array}$ & $\begin{array}{l}\text { Total investment } \\
\text { (million yuan) }\end{array}$ & $\begin{array}{l}\text { Starting } \\
\text { month }\end{array}$ \\
\hline $\begin{array}{l}\text { Maoxian } \\
\text { Stadium }\end{array}$ & $\begin{array}{c}\text { Jingzhou Village, } \\
\text { Fengyi Town, Mao } \\
\text { County }\end{array}$ & $\begin{array}{c}5,000 \text { seats, } \\
\text { construction area of } \\
10,000 \text { square } \\
\text { meters and } \\
\text { equipment }\end{array}$ & 30 & May of 2009 \\
\hline $\begin{array}{c}\text { Maoxian Indoor } \\
\text { National Fitness } \\
\text { Center }\end{array}$ & $\begin{array}{c}\text { Jingzhou Village, } \\
\text { Fengyi Town, Mao } \\
\text { County }\end{array}$ & $\begin{array}{c}\text { Large-scale } \\
\text { construction and } \\
\text { equipment with a } \\
\text { construction area of } \\
3,000 \text { square meters }\end{array}$ & 8 & May of 2009 \\
\hline $\begin{array}{c}\text { Maoxian } \\
\text { Gymnasium }\end{array}$ & $\begin{array}{c}\text { Jingzhou Village, } \\
\text { Fengyi Town, Mao } \\
\text { County }\end{array}$ & $\begin{array}{l}2000 \text { seats, } 6,000 \\
\text { square meters of } \\
\text { construction area } \\
\text { and } 1,500 \text { square } \\
\text { meters of ancillary } \\
\text { equipment }\end{array}$ & 24 & May of 2009 \\
\hline $\begin{array}{c}\text { Student } \\
\text { Dormitory of } \\
\text { Maoxian Sports } \\
\text { School } \\
\end{array}$ & $\begin{array}{c}\text { Jingzhou Village, } \\
\text { Fengyi Town, Mao } \\
\text { County }\end{array}$ & $\begin{array}{l}\text { Construction and } \\
\text { equipment of } 800 \\
\text { square meters }\end{array}$ & 1.2 & May of 2009 \\
\hline
\end{tabular}

\subsection{Appropriate climate meeting the conditions of plateau training}

Geographical and climatic conditions have a great impact on sports training. Especially the climatic conditions including temperature, precipitation, wind and solar radiation in the plateau environment directly affect the training arrangements and effects. To establish a plateau training base, it is necessary to understand the local climatic characteristics.

\subsubsection{Climate characteristics of Barkam County}

The county belongs to the plateau valley area, and the terrain gradually decreases from northeast to southwest. Its elevation is between 2180 meters and 5301 meters. Its climate is plateau monsoon climate, and it is "wet and cold in winter, dry and cool in summer, and has rain and high heat in the same season, sufficient sunshine and large temperature difference between day and night", with four distinct seasons. The average annual precipitation is $753 \mathrm{~mm}$, the annual average temperature is $8.6^{\circ} \mathrm{C}$, the average annual sunshine is over 2,000 hours, and the absolute frost-free period is 120 days. Its air quality reaches the national level I standard. The climatic conditions in Wenchuan, Lixian and Maoxian are relatively ideal. The significant vertical zonality plays an obvious role in improving athletes' body metabolism and promoting athletes' physiological function change. In addition, the annual average temperature here is about $15^{\circ} \mathrm{C}$, the summer temperature is low, the daily temperature difference is over $10^{\circ} \mathrm{C}$, and the climate meets the requirement of plateau training, so that it is an ideal sub-plateau training place.

\subsubsection{Climate of Wenchuan County}

The annual precipitation of Wenchuan is $392 \mathrm{~mm}$, the evaporation is $1627 \mathrm{~mm}$, the annual average vapor pressure is $11.4 \mathrm{mbar}$, the relative humidity is $63 \%$, the average wind speed is $1.3 \mathrm{~m} / \mathrm{s}$, and the sunshine hours are 1280. Wenchuan is suitable for training from March to November, the average temperature is $18.4^{\circ} \mathrm{C}$, the temperature is higher, the air is more humid, the climatic conditions from March to November are suitable for plateau training, and the time suitable for plateau training is longer, so the training value is high. 


\subsubsection{Climate of Maoxian County}

At present, plateau training bases in the world tend to be built in the areas with higher temperature and greater air humidity. Areas of low latitude and high altitude mostly have rainy weather and hot and humid weather, bringing some unfavorable factors to plateau training. The areas with high latitude and high altitude or mid-latitude and high altitude, due to the impact of different factors such as mountains, lakes, rivers and cities, are possible to form climatic conditions that are conducive to plateau training.

1) Sunshine

The average annual sunshine hours of the county are 1,554.1 hours, with a maximum of $1,758.3$ hours per year and a minimum of 1,386.1 hours per year. The sunshine hours in August is the maximum, 162.3 hours, followed by 154.4 hours in July, while the sunshine hours in September is the minimum, 92.4 hours. In terms of seasonal distribution, sunshine in the summer is the most, followed by spring, and autumn has the least sunshine. Low temperature and rain of September and October cause a decrease in sunshine and insufficient heat. The annual sunshine percentage of the county is $35 \%$. The highest sunshine rate is in December, $46 \%$, followed by $42 \%$ in January, and only $25 \%$ in September.

2) Temperature

Annual and Monthly Average Temperature From 1985 to 1986 , the annual average temperature in the suburbs was $11.1^{\circ} \mathrm{C}$, and the warmest annual average temperature was $11.8^{\circ} \mathrm{C}$, appearing in 1953 and 1963 . The coldest annual average temperature was $10.3^{\circ} \mathrm{C}$, appearing in 1976 and 1984, and the temperature difference between cold and warm annual average temperature is $1.5^{\circ} \mathrm{C}$. The hottest month in the county is July, with the average temperature of $20.7^{\circ} \mathrm{C}$, followed by August, with the average temperature of $20.2^{\circ} \mathrm{C}$; the coldest month is January, with the average temperature of $0.4{ }^{\circ} \mathrm{C}$, and the annual temperature difference is $20.3{ }^{\circ} \mathrm{C}$.

3) Wind

The wind direction of Fengyi area is mainly nearly east, and the wind out of the valley is more prominent. The trees in the wind outlets are flag-shaped and incline to the southwest. It is the largest wind speed area in the province, with an annual average wind speed of $4 \mathrm{~m} / \mathrm{s}$. The wind speed of spring is larger, with the largest wind speed in March, $4.7 \mathrm{~m} / \mathrm{s}$ of monthly average; the minimum in September, $3.5 \mathrm{~m} / \mathrm{s}$. Cold and warm air activities are frequent in spring, the pressure gradient is large, the wind speed changes are small wind speed in the morning and evening and large wind speed in the afternoon, and the frequency is $26 \%$. The dominant wind direction from January to March and from October to December is east, the frequency is generally $27 \sim 29 \%$, and the rest of the months is partially east wind.

4) Snowfall and Snow Cover

The average number of snowfall days in the Fengyi area is 20.1 days. The snowfall weather mainly occurs from November to March of the following year. The average first snow date is November 28, the earliest snow date is November 8 , the average last snow date is March 8 , and the latest snow date is April 5. The average annual snow cover is 15.4 days. The deepest snow depth is $7 \mathrm{~cm}$, appearing on February 17, 1954 and December 28, 1983.

\subsection{Humanistic advantages of tibetan gathering area}

The Western Sichuan Plateau is not only famous for its unique topographical feature, mountains and valleys integration, but also for its role of important cultural corridor and ethnic corridor connecting the Yellow River and the Yangtze River. Maoxian County, located in this important area, has been the main settlement of the Qiang people since the ancient times. In the long history, many ethnic groups have lived here. Their cultures are spread and developed here, becoming an important part of the multi-cultural integration of the Chinese nation. The cultural essence of the Tibetan and Qiang people here has become a hot spot of many scholars' attention and research. China has established a national sports regional activity center represented by the national sports training base, fully explored the connotation of traditional sports of ethnic minorities, summarized and improved the traditional sports of ethnic minorities, incorporated them into the modern sports category, and promoted and popularized traditional sports of ethnic minorities, which are of great significance to the implementation of national fitness and the promotion of national culture.

\section{Measures and suggestions for the construction of the Aba sub-plateau base}

1) Build a high-standard training base integrating competitive sports, national fitness, national sports, sports training and health care.

2) Form a training community of Wenchuan-Maoxian-Barkam Plateau. The sub-plateau training base is centered on Maoxian County. With its unique location advantages, good humanistic natural environment and good sports facilities, as well as the reputation of "track and field hometown of Aba Prefecture", Maoxian County will surely attract more attention from sports teams. Maoxian is expected to develop into the most characteristic plateau training base for professional sports team in Sichuan Province.

3) To establish Sichuan Sub-plateau Training Base, it is necessary to obtain policy and financial support from the local government of Aba Prefecture and provincial and municipal sports bureaus, and establish an industry-university-research system with Aba Teachers University and Chengdu Sport University in Aba Prefecture. The establishment of sub-plateau training laboratory requires the approval of the State General Administration of Sport.

4) Construct traditional ethnic sports training bases of Tibetan and Qiang Nationality. The implementation of the project will greatly promote the development of ethnic traditional sports in Aba Prefecture. The construction of the ethnic sports training base can provide sufficient guarantee for the training of ethnic sports in ethnic areas and can also reserve ethnic sports talents for 
various regions, which can improve the competitive level of traditional sports of ethnic minorities, and guarantee the sustainable development of minority sports.

5) Integrate the Qiang people's eco-tourism, inspection, leisure, vacation, cultural exchange, health care and old-age care with the Aba Sub-plateau training base. The construction of the base highlights the cultural characteristics of the Tibetan and Qiang Nationality; it is necessary to make reasonable plans for the stadium and the surrounding environment, to meet the requirements of the development of the sports industry.

In short, from the perspective of system, and based on the environmental characteristics and interest analysis of Wenchuan and surrounding areas, it is recommended to establish Wenchuan sub-plateau training bases, including Shuimo, Weizhou (Wenchuan)-Fengyi (Maoxian County)-Barkam staged training base, establish a sub-plateau training base for minority sports of Tibetan and Qiang Nationality in Aba Teachers University (Shuimo), establish a comprehensive sub-plateau training base dominated by track and field in Maoxian County, and establish a comprehensive plateau training base in Barkam County.

Fund project: Research on the Construction of Aba Sub-plateau Health Care and Training Base (TY2018202), key project of Key Research Base of Sports Humanities and Social Sciences, Sichuan Provincial Ministry of
Philosophy, Social Sciences and Education, the research result of the sub-team, Creative Industry Development Research Team of Sports Culture of Tibet-Qiang-Yi Corridor of Sichuan, of high-level research team of social sciences in Sichuan, Creative Industry Development Research Team of Culture of Tibet-Qiang-Yi Corridor of Sichuan (2018-2020).

\section{References}

1. Yu Zongxian, Song Tianhua. Research on the Evaluation and Development of Wenchuan Sub-plateau Training Base Construction and Sports Resources [J]. Economic Research Guide. 2010.09

2. Feng Lianshi. Plateau Training [J] China Sport Science and Technology 1999.04

3. Sheng Jianguo. Analysis on the Basic Conditions of Yuzhong Plateau Training Base in Gansu Province [J]. China Sport Science and Technology. 2003.01

4. Zhao Jin, Kong Chuihui. Review of the Impact of Plateau Environment on Sports Training [J]. Journal of Beijing Sport University. 2005.01

5. Wang Guizhong. Research on the Necessity of Establishing Traditional Sports Training Bases of Minority Nationalities [J]. Sichuan Sports Science. 2003.09 